\title{
Study on Hand Greater Yang Skin from the Viewpoint of Human Anatomy
}

\author{
Kyoung-Sik, Park ${ }^{1}$ \\ ${ }^{1}$ Dept. of Anatomy, College of Korean Medicine, Sangji University
}

\begin{abstract}
Objectives: This study was carried out to analyse Hand Greater Yang Skin in human.
Methods: Hand Greater Yang meridian was labeled with latex in the body surface of the cadaver. And subsequently body among superficial fascia and muscular layer were dissected in order to observe internal structures.

Results : A depth of Skin encompasses a common integument and a immediately below superficial fascia, this study established Skin boundary with adjacent structures such as relative muscle, tendon as compass. The Skin area of the Hand Greater Yang in human are as follows: The skin close to 0.1 chon ulnad of $5^{\text {th }}$ nail angle, ulnad base of $5^{\text {th }}$ phalanx, ulnad head of $5^{\text {th }}$ metacapus(relevant muscle: abductor digiti minimi muscle), ulnad of hamate, tip of ulnar styloid process(extensor carpi ulnaris tendon), radiad of ulnar styloid process, $2 \mathrm{~cm}$ below midpoint between Sohae and Yanggok(extensor carpi ulnaris), between medial epicondyle of humerus and olecranon of ulnar(ulnar nerve), The skin close to deltoid muscle, trapezius muscle, platysma muscle, inner muscles such as teres major muscle, infraspinatus muscle, supraspinatus muscle, levator scapulae muscle, splenius cervicis muscle, splenius capitis muscle, sternocleidomastoid muscle, digastric muscle, stylohyoid muscle, zygomaticus major muscle, auricularis anterior muscle.

Conclusions: The Skin area of the Hand Greater Yang from the anatomical viewpoint seems to be the skin area outside the superficial fascia or muscles involved in the pathway of Hand Greater Yang meridian, collateral meridian, meridian muscle, with the condition that we consider adjacent skins.
\end{abstract}

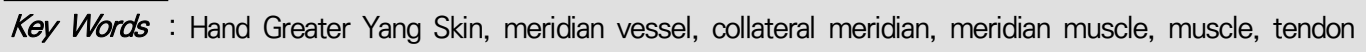

\section{Introduction}

According to the Skin theory of Su wen that alludes to the existence of Skin, Skin seems to be closely linked to meridian vessel, especially collateral meridian, float meridian or twig meridian. belonging to meridian vessel. but it tend to show the property of more of face than line, dispersing on body surface, in comparison with meridian vessel ${ }^{1,2)}$.
One of the major concerns regarding Skin is major role of barrier for xie qi attack. Twig meridian contacts external pathogens at first, an disease of internal organ is also reflected on specific area of the body surface, therefore it is impossible to apply Skin theory to diagnosis and treatment of disease, regardless of the systemic or local concept of Skin ${ }^{3)}$. According to the Skin theory of Su wen, Skin composes of various intrinsic realms. If we do not cure a disease on this intrinsic

\footnotetext{
- Received : 28 November 2018

- Revised : 14 December 2018

- Accepted : 14 December 2018

- Corresponding author; Kyoung-Sik, Park

Dept. of Anatomy, College of Korean Medicine. Sangji University, WonJu, Republic of Korea

Tel: +82-33-730-0667, Fax: +82-33-730-0667, Email: ksikpark@sangji.ac.kr
} 
realm, there will be serious consequences, and also this record mentions that xie qi on Skin maked an intrusion on the internal part of the body via collateral meridian and then a new crisis might arises in Zangfü ${ }^{6,7}$.

It is important to study on Skin, especially Hand Greater Yang Skin, but there are few works ${ }^{1,4)}$ that present the definite realme of Skin. Lee DS Et al. ${ }^{4}$ explain that Skin and collateral meridian is situated on a hypodermis or superficial fascia, on the other hand Lee $\mathrm{DH}^{5)}$ argues that Skin transpierces a adjacent muscle, and also Hong $\mathrm{WS}^{6}$ ) says that meridian vessel travels hidden in intermuscular space, therefore it is not seen, but collateral meridian may be seen. According to a few workers ${ }^{2,7,8)}$ they say that Skin is the collateral meridian of 12 meridian vessels. Meridian chapter of Lingshu says that 12 Skins and 12 meridian muscles are continuous part of 12 meridian vessels. Herein it seems that the realm of 12 Skins is also related to that of 12 meridian muscles ${ }^{1)}$.

For these reasons, it is possible to guess the realme of Hand Greater Yang Skin, based on Hand Greater Yang meridian vessel, its collateral meridian, and its meridian muscle etc.

This study makes an attempt to set up the true nature of Hand Greater Yang Skin on the ground of existing theories, in consideration of meridian vessel, meridian muscle, especially collateral meridian.

\section{Materials and methods}

\section{Preservative preparations and injection}

1) The preparation of a preservative phenol was dissolved in methyl alcohol at the rate of one to one $\mathrm{W} / \mathrm{V}$ (The 1st solution).

Glycerin was dissolved in methyl alcohol at the rate of one to four $\mathrm{V} / \mathrm{V}$ and thereafter additional same amounts of glycerin was dissolved in this solution (the 2nd solution). The 1 st and 2 nd solutions were mixed well, and warmed $(30 \mathrm{~min}, 20$ ${ }^{\circ} \mathrm{C}$ ). Same amounts of of methyl alcohol was added to this mixed solution and stirred for 10 minutes. Finally additional 1.5 times of formalin was added to the mixed solution.

\section{2) Injection to cadaver}

The sheath of the femoral artery \& vein was exposed by vertical incision at the medial third of the inguinal ligament, and the femoral artery was carefully separated from the femoral vein. A preservative was injected into the femoral artery at a speed of $150 \mathrm{ml}$ per minute. After $6 \ell$ of preservative was injected, the needle-inserted part was ligated, and subsequently an injector needle was inserted downwards for the preservation of the leg.

\section{Embalmment of cadaver}

1) Cadaver was pending in the embalmment system for $40 \mathrm{hrs}$ at $40^{\circ} \mathrm{C}$.

2) Cadaver was exposed for $1 \mathrm{hr}$ at room temperature, and after that, kept in refrigerated storage $\left(3{ }^{\circ} \mathrm{C}, 30 \%\right.$ humidity).

\section{Experimental procedure}

1) The Hand Greater Yang meridian was labeled with latex in the body surface of the cadaver.

2) Meridian points were based on Korean Standard Acupuncture Point Location".

3) Pores were made by a drill in the vertical direction at each meridian point.

4) Skin and superficial fascia were dissected in order, investigating vessels and nerves and the exposed deep fascia thereafter 
labeled by latex, and then deep fascia was removed.

5) Subsequently muscle with vessels and nerves were investigated.

\section{Result}

There seems to be Skin in the depth level of superficial fascia from the antomical viewpoint, but it is difficult to define its position concretely. This study states Skin as boundry or territory with adjacent structures such as muscle, ligament, bone. From the antomical point of view Skin area assumed belong to the skin of the Hand Greater Yang are as follows:

The skin close to 0.1 chon ulnad of $5^{\text {th }}$ nail angle, ulnad base of $5^{\text {th }}$ phalanx, ulnad head of $5^{\text {th }}$ metacapus (relevant muscle: abductor digiti minimi muscle), ulnad of hamate, tip of ulnar styloid process(extensor carpi ulnaris tendon), radiad of ulnar styloid process, $2 \mathrm{~cm}$ below midpoint between Sohae and Yanggok(extensor carpi ulnaris), between medial epicondyle of humerus and olecranon of ulnar(ulnar nerve), the skin close to deltoid muscle, trapezius muscle, platysma muscle, inner muscles such as teres major muscle, infraspinatus muscle, supraspinatus muscle, levator scapulae muscle, splenius cervicis muscle, splenius capitis muscle, sternocleidomastoid muscle, digastric muscle, stylohyoid muscle, zygomaticus major muscle, auricularis anterior muscle.

\section{Discussion}

With regard to Skin, this term is recorded in the Skin theory of Suwen for the first time. But it is just a sweeping remark with assumed atlas ${ }^{4}$, definite concept is not unknown.

The literatures of this subject state that meridian vessel is longitudinal, whereas collateral meridian is horizonal, superficial, collateral branch of 12 meridian vessels is Skin ${ }^{7,8,10)}$. Meridian muscle is skeletal system belong to meridian system, and also 12 meridian muscles and 12 Skins area are similar to those of 12 meridian vessels $^{1,10)}$, collateral meridian distributed to body surface is also referred to 12 meridian muscles and 12 Skins $^{8)}$. Herein the realm of Skin may be associated with meridian muscle and collateral meridian in addition to meridian vessel.

According to the Skin theory of Su wen, if external affection trespasses on the skin, superficial fascia is open, if flesh is open, external affection stays to collateral meridian, if collateral meridian is filled with external affection, external affection enters external affection, vessel, if meridian vessel is filled with external affection, external affection stays to organ. Symptoms concerned to Hand Greater Yang Meridian are bizheng or fenghanshi block to meridian vessel, and are accompanied by laryngopharyngeal pain, buccal swelling or pain or neck pain, shoulder pain, colicky pain, diarrhea. In case of energy deficiency of Hand Greater Yang collateral Meridian, warts or lumps are more formed ${ }^{1,11}$.

We could guess the realm of Skin, in consideration of the correlation among the Skin, meridian muscle, collateral meridian and disease syndroms etc. on the basis of meridian vessel. We referred to universal literatures ${ }^{1,412)}$ for the pathway of Hand Greater Yang meridian vessel, meridian muscle, collateral meridian, and atlases for the realme of Hand Greater Yang Skin ${ }^{14}$.

Arm and neck regions appear clear divisions between Hand Lesser Yang Skin and Hand Lesser Yin Skin or Leg Lesser Yang Skin and Hand Lesser Yang Skin, but shoulder and face regions appear unclear divisions.

\section{Conclusion}

This study was carried out to analyse Hand Greater Yang Skin in human, dissecting and splitting a body 
among superficial fascia and muscular layer in order to expose inner structures such as muscles, nerves, blood vessel related to Hand Greater Yang Skin. We obtained the conclusions as follows:

1. The skin area of Hand Greater Yang in human seemed to be closely matched to main meridian vessel, collateral meridian, meridian muscle as a part of the meridian system. To put it more concretely, including the skin close to 0.1 chon ulnad of $5^{\text {th }}$ nail angle, ulnad base of $5^{\text {th }}$ phalanx, ulnad head of $5^{\text {th }}$ metacapus(relevant muscle: abductor digiti minimi muscle), ulnaris of hamate, tip of ulnar styloid process(extensor carpi ulnaris tendon), radiad of ulnar styloid process, $2 \mathrm{~cm}$ below mid point between Sohae and Yanggok(extensor carpi ulnaris), between medial epicondyle of humerus and olecranon of ulnar(ulnar nerve), and the skin close to deltoid muscle, trapezius muscle, platysma muscle, inner muscles such as teres major muscle, infraspinatus muscle, supraspinatus muscle, levator scapulae muscle, splenius cervicis muscle, splenius capitis muscle, sternocleidomastoid muscle, digastric muscle, stylohyoid muscle, zygomaticus major muscle, auricularis anterior muscle.

2. With regard to the realm of Hand Greater Yang Skin, Arm and neck regions appear clear divisions between Hand Lesser Yang Skin and Hand Lesser Yin Skin or Leg Lesser Yang Skin and Hand Lesser Yang Skin, but shoulder and face regions appear unclear divisions.

3. From the viewpoint of human anatomy, Hand Greater Yang Skin in human appears to be made up of the histological common integument, superficial fascia in depth, including the relevant nerves or blood vessels.

\section{References}

1. The Department Alliance of Acupuncture \& Moxibustion, Oriental Medicine. Zhenjiuxue (Acupuncture \& Moxibustion, the 1st volume). 3Eds. Seoul:Gypmundang. Co. 1991:45-47, 64,155, 171-174, 515-527, 661-680.

2. Jo SM. The piece translated into Korean, Suwen (or Basic Questions) of HUANGDI NEIJING with commentary by Maoshing ni. Seoul:Cheong Hong Publishing Ins. 2012:94, 308-317.

2. Bae BC. The piece translated into Korean, Suwen of HUANGDI NEIJING. Seoul:Korea Bio Medical Science Institute. 2000:248-251.

3. Institute of Korea Traditional Medicine. Introduction to Korean Medicine. Seoul:Younglimsa. 2007:94.

4. Lee DS Etc. Principles and Practice of the Meridian. Seoul:Hoonminsa Co. 2004:167, 314-326.

5. Lee DH. A Comforting Hand Meridian Theory. SPAGON Publishing Inc. 2005:78.

6. Hong WS. Lingshu (or Divine Pivot) of HUANGDI NEIJING. Seoul:Komoonsa Co. 2010:139.

7. Park CG. Suwen of HUANGDI NEIJING. Seoul:Editorial department, Kyunghee University. 1998:88-95, 119-122.

8. Shanghai Zhongyi Xueyuan (College of Chinese medicine). Acupuncture \& Moxibustion. Beijing:Renmin Weisheng Publications Ins. 1974:81, 89-90.

9. Shon IC, 25 of editing commissioners. Korean Standard Acupuncture Point Location. Korean society of meridian \& acupoint, Korean acupuncture $\&$ moxibustion society, Korea institute of oriental medicine. 2006:1-67.

10. BaeBC. The piece translated into Korean, Suwen of HUANGDI NEIJING. Seoul:Korea Biomedical Science Institute. Seongbosa. 2001:623.

11. Shon IC, Lee MH. The theory of Meridian Relation, 
The piece translated into Korean, KEIRAKU SOKANLON by Hironari Oda. Seoul:Cheong Hong Publications Ins. 2013:61-63, 196-200, 520.

12. Ahan YK. A Collection of Meridian Acupoint. Seoul:Sungbosa 1991:281-320.

13. Netter FH. Atlas of human anatomy. CIBA. 1987:Plate 17-23, 31, 396-402, 424-425, 450-456.

\section{ORCID}

Kyoung-Sik, Park: https://qa.orcid.org/0000-0001-9447-4730 